\title{
SOEP
}

SOEPpapers

SOEPna Pars
on Multidisciplinary Panel Data Research
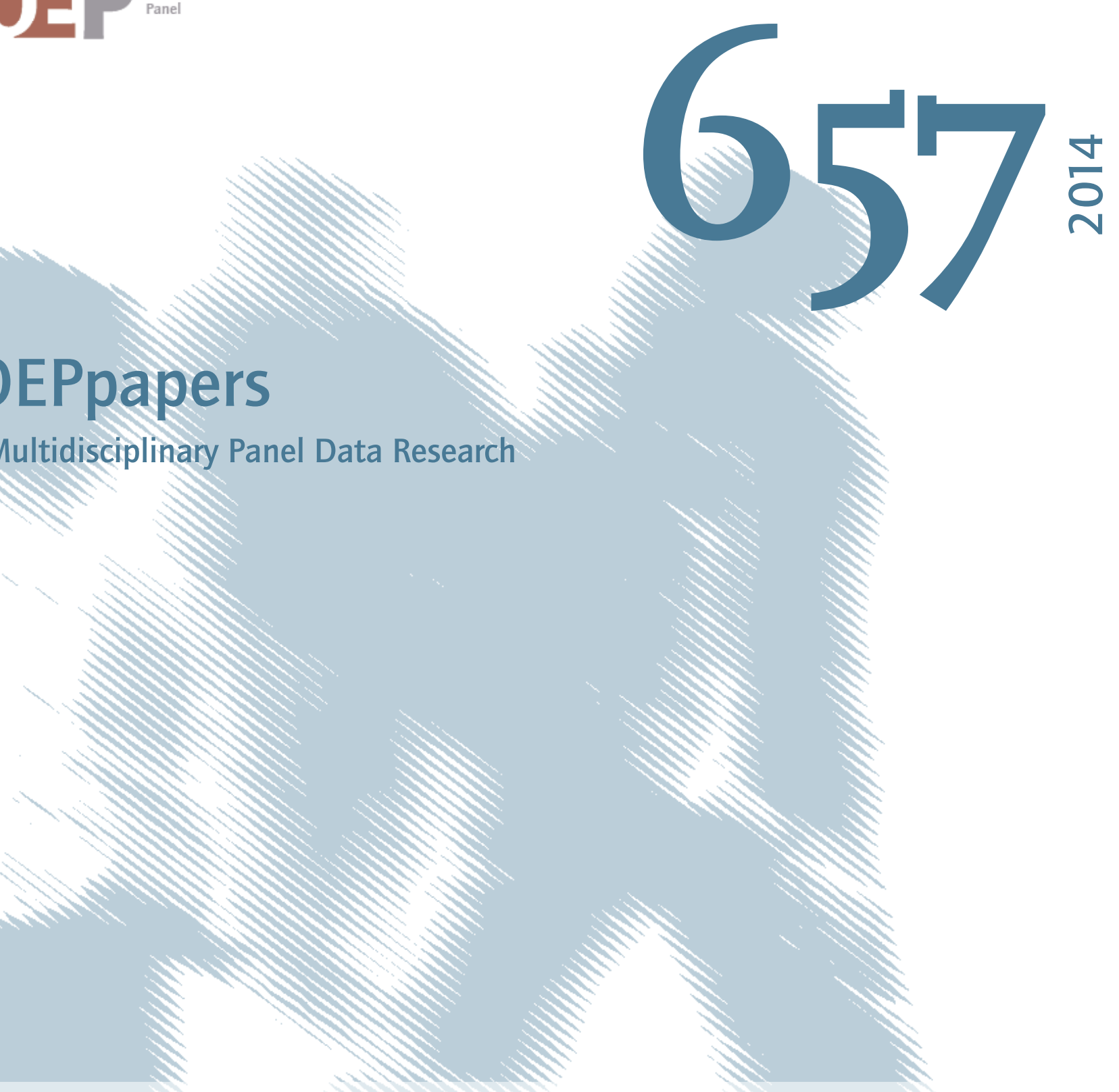

\section{Longitudinal Transactions Between Personality and Occupational Roles: A Large and Heterogeneous Study of Job Beginners, Stayers, and Changers}




\section{SOEPpapers on Multidisciplinary Panel Data Research}

at DIW Berlin

This series presents research findings based either directly on data from the German SocioEconomic Panel Study (SOEP) or using SOEP data as part of an internationally comparable data set (e.g. CNEF, ECHP, LIS, LWS, CHER/PACO). SOEP is a truly multidisciplinary household panel study covering a wide range of social and behavioral sciences: economics, sociology, psychology, survey methodology, econometrics and applied statistics, educational science, political science, public health, behavioral genetics, demography, geography, and sport science.

The decision to publish a submission in SOEPpapers is made by a board of editors chosen by the DIW Berlin to represent the wide range of disciplines covered by SOEP. There is no external referee process and papers are either accepted or rejected without revision. Papers appear in this series as works in progress and may also appear elsewhere. They often represent preliminary studies and are circulated to encourage discussion. Citation of such a paper should account for its provisional character. A revised version may be requested from the author directly.

Any opinions expressed in this series are those of the author(s) and not those of DIW Berlin. Research disseminated by DIW Berlin may include views on public policy issues, but the institute itself takes no institutional policy positions.

The SOEPpapers are available at

http://www.diw.de/soeppapers

\section{Editors:}

Jürgen Schupp (Sociology)

Gert G. Wagner (Social Sciences, Vice Dean DIW Graduate Center)

Conchita D'Ambrosio (Public Economics)

Denis Gerstorf (Psychology, DIW Research Director)

Elke Holst (Gender Studies, DIW Research Director)

Frauke Kreuter (Survey Methodology, DIW Research Professor)

Martin Kroh (Political Science and Survey Methodology)

Frieder R. Lang (Psychology, DIW Research Professor)

Henning Lohmann (Sociology, DIW Research Professor)

Jörg-Peter Schräpler (Survey Methodology, DIW Research Professor)

Thomas Siedler (Empirical Economics)

C. Katharina Spieß (Empirical Economics and Educational Science)

ISSN: 1864-6689 (online)

German Socio-Economic Panel Study (SOEP)

DIW Berlin

Mohrenstrasse 58

10117 Berlin, Germany

Contact: Uta Rahmann | soeppapers@diw.de 
IN PRESS (Developmental Psychology)

COPYRIGHT@American Psychological Association

http://www.apa.org/pubs/journals/dev/

This article may not exactly replicate the final version published in the APA journal.

It is not the copy of record.

DOI 10.1037/a0036994

Longitudinal Transactions Between Personality and Occupational Roles: A Large and

Heterogeneous Study of Job Beginners, Stayers, and Changers

Jaap J. A. Denissen

Tilburg University

Hannah Ulferts

Free University Berlin

Oliver Lüdtke

Humboldt-University Berlin

Peter M. Muck

Federal Employment Agency, Germany

Denis Gerstorf

Humboldt-University Berlin 


\begin{abstract}
Social norms are central to theoretical accounts of longitudinal person-environment transactions. On the one hand, individuals are thought to select themselves into social roles that fit their personality. On the other hand, it is assumed that individuals' personality is transformed by the socializing pressure of norm demands. These two transactional directions were investigated in a large and heterogeneous 5-year longitudinal subsample of job beginners $(n=640, M$ age $=21.24)$, job stayers $(n=4,137, M$ age $=46.63)$, and job changers $(n=2,854, M$ age $=44.68)$ from the German Socio-Economic Panel. Role demands were coded by both students and labor market experts. To demonstrate transactional effects, crosslagged structural equation models were estimated. Substantial selection effects were found for both job beginners and job changers. There was also evidence for socialization effects, especially for participants who did not change jobs. Depending on the trait and the subsample that was investigated, selection effects were sometimes corresponsive with socialization effects. Personality role demands were temporally consistent across a four-year period even when individuals changed jobs (heterotypic continuity). This is one of the first empirical demonstrations of the transactional processes that lead to the formation of social niches.
\end{abstract}

\title{
195 Words
}

Keywords: Personality development, person-environment transactions, job characteristics, occupational roles, longitudinal study 
Human beings can be regarded as open systems that are continuously interacting with the world around them (Baltes, 1987). Social Investment Theory (Roberts, Wood, \& LodiSmith, 2005) predicts that people invest in and internalize the demands and expectations that come with the assumption of social roles, which in turn promotes accommodating personality change. Other scholars have argued for the impact of stable personality traits that prompt individuals to actively select and change environments that fit their personality (Buss, 1987; Scarr \& McCartney, 1983). The current study set out to study differences in the relative impact of different kinds of person-environment transactions within a key domain of adult development, namely the occupational context, using a large and heterogeneous longitudinal sample of job beginners, stayers, and changers.

\section{Person-Environment Transactions in the Occupational Context}

The present study focused on job characteristics as a context for personality development for a number of reasons. Foremost, most people spend a large proportion of their adult time in occupational contexts, which are of great relevance for one's identity (Meeus, 1993). The occupational context is also a domain with relatively clearly articulated norms and expectations (often formalized into the curricula of professional schooling). The occupational contexts therefore seems a suitable testing ground for theoretical accounts that stress the importance of social norms in describing transactions between persons and environments.

Consistent and cumulative persons-environments transactions can lead to an increasing fit between the person and the job environment (Cooper-Thomas, van Vianen, \& Anderson, 2004; Edwards, Cable, Williamson, Lambert, \& Shipp, 2006). Fit has been operationalized in terms of the correspondence between job characteristics and workers' vocational interests (Holland, 1987). In spite of clearly documented associations between vocational interests, abilities, and personality traits (Ackerman, 1996; Larson, Rottinghaus, \& Borgen, 2002), relatively little is known about person-environment fit between job 
requirements and Big Five personality traits (for an exception, see Ehrhart \& Makransky, 2007). Moreover, it is unclear whether processes of socialization or selection can account for the evolvement of person-environment fit, which is the goal of the present study.

Person-environment fit in the occupational context can increase due to five processes (for corresponding models see Schneider, 1987; Schneider, Smith, Taylor, \& Fleenor, 1998; Roberts, 2006). First, vocational psychology has traditionally focused on job selection as a prominent force of increasing person-environment fit (George, Helson, \& John, 2011; Hurtz, \& Donovan, 2000; Ones, Dilchert, Viswesvaran, \& Judge, 2007; Rothstein \& Goffin, 2006). Second, people are attracted to certain organizations that seem likely to reinforce their personality traits. Third, individuals with personality traits that do not match the organization can leave the organization. Fourth, people's personality can be transformed by their occupational environment. Finally, people manipulate and thereby actively change their environment. Evidence regarding these different types of transactions, which are the focus of the present paper, is summarized in the following.

A multitude of different factors are known to influence vocational choice, among them interest, self-concept of ability, vocational choice intentions, and self-efficacy (for theoretical overviews, see Eccles, 1994; Holland, 1959; Kanfer, Wanberg, \& Kantrowitz, 2001; Super, 1953). Personality characteristics constitute another set of variables that are uniquely associated with vocational choice. Consistent with this idea, Roberts, Caspi, and Moffitt (2003) found associations between age 18 personality and age 26 work characteristics, which were interpreted as selection effects. Specifically, negative emotionality (a trait that is closely related to neuroticism) predicted lower levels of subsequent occupational attainment, work satisfaction, and financial security. In contrast, constraint at age 18 (a trait that is closely related to conscientiousness) was found to predict higher levels of the same outcomes, in addition to higher levels of work involvement. Finally, agency (a facet of extraversion) positively predicted all work outcomes (except for financial security), whereas the predictive 
validity of communion (related to agreeableness) was limited to occupational attainment, work satisfaction, financial security, and work stimulation.

Within the field of personality development, Social Investment Theory (Lodi-Smith \& Roberts, 2007; Roberts et al., 2005) emphasizes how people's identification with and investment in mature social roles can lead to change in personality traits. Specifically, the social environment is expected to react with affirmation and rewards to behavior that is consistent with social roles, whereas behavior that departs from these roles is thought to be followed by social disapproval. Some longitudinal studies have indeed confirmed roleaccommodating personality changes in novice professionals (Cartwright \& Wink, 1994; Eli \& Shuval, 1982).

Complementary to a socialization perspective, it is also possible that people transform the nature of the jobs they occupy. For example, Sutin and Costa (2010) found that personality characteristics significantly predicted changes in job characteristics, with extraversion, conscientiousness, emotional stability, and openness predicting increases in decision latitude, extraversion predicting a decrease in hazardous work, and agreeableness predicting a decrease in physical demands. In addition, Hudson, Roberts, and Lodi-Smith (2012) found that initial agreeableness levels are associated with increases in social investment in work, and Wille, Beyers, and de Fruyt (2012) found that personality affects changes in career roles. It is somewhat difficult, however, to interpret these findings, because they are based on self-reported work characteristics. As was found by Harms, Roberts, and Winter (2006), people are likely to change their perception of the environment in order to achieve a feeling of congruence with their self-perceived needs. This shared method variance could affect cross-lagged associations between personality and self-reported environmental features. Such method effects can only be avoided if personality and environmental measures are based on different sources of information, as is done in the present study. 
Longitudinal Transactions 6

In the above studies, individuals were followed within their existing jobs. Associations between personality and changes in job characteristics may thus represent an example of "job crafting": changing the features of one's existing job to better match one's abilities and aspirations (Wrzesniewski, 2001). Another way in which personality characteristics can initiate changes in the vocational environment, and the one that is thus focus of the present study, is by promoting a change of jobs. There are some indications that people actually change environments when they do not concur with their personality. In a seminal study, Holland and Nichols (1964) found that students who were more dissimilar to a typical student in their academic field were more likely to change their major field of study. Within the occupational domain, Assouline and Meir (1987) reported a meta-analytic correlation of .15 between job stability and person-environment congruence. More important for a transactional perspective, however, is the question whether individuals, after leaving a job because of low congruence, actually select themselves into a job with higher subsequent congruence. There are only two studies that indirectly address this question. Specifically, both Oleski and Subich (1996) and Donohue (2006) sampled descriptions of actual versus intended jobs in individuals contemplating a career change and found that intended jobs provided a closer fit to their interests than current jobs did. To the best of our knowledge, there are no studies that have directly investigated whether individuals follow up on this intention and actually select themselves into more congruent jobs, however.

\section{Types of Longitudinal Person-Environment Transactions}

Zooming out again, the study of the interplay between personality and occupational factors is relevant for two important general transactional principles (see Woods, Lievens, de Fruyt, \& Wille, 2013, for a review of such principles in occupational psychology). The first principle concerns the question of how the stability of interacting systems affects their relative influence on each other. It has been argued that systems with a greater degree of continuity are more likely to affect systems with a lesser degree of continuity because the former are 
more likely to affect the latter in a consistent and cumulative way (Asendorpf \& van Aken, 2003; Fraley \& Roberts, 2005). Meta-analytic evidence indicates that personality stability is substantial, with test-retest stabilities increasing from .35 in childhood to .75 in late adulthood (Roberts \& DelVecchio, 2000). While these numbers are not sufficiently high to preclude rank-order personality change (a prerequisite of differential socialization effects), they make it plausible that the personality system can exert cumulative effects on environmental factors (McCrae et al., 2000).

Far less is known, however, about the stability of environmental factors. This is an extremely thorny issue that can be investigated on various levels. The approach that we take in the present paper focuses on discrete environments (i.e., job titles). If the description of these discrete environments changes (e.g., if a person enters a job as software engineer after previously having worked as a nurse), this brings about a change in environmental factors. This kind of nominal environmental change may mask an underlying continuity of psychological factors between the old and the new environment, however. For example, if one starts a job as social worker after having worked as a nurse, the old job is likely similar to the new job in terms of an importance to care for the well-being of other people (heterotypic continuity). Because job characteristics are dependent on a host of factors other than individuals' personality, however, it can be expected that the heterotypic continuity of occupational role demands is lower than the continuity of personality.

The second principle that has been shown to underlie person-environment transactions is the so-called corresponsive principle (Roberts, Wood, \& Caspi, 2008). This principle states that the same traits that select people into certain environments are amplified as a result of being influenced by these environments. There are several strains of evidence that are consistent with this principle. For example, Mortimer and Lorence (1979) found that the work values that predicted certain work experiences in turn deepened these initial work values. For example, having a highly extrinsic work value was associated with relative increases in 


\section{Longitudinal Transactions 8}

income, which was in turn associated with a further increase in extrinsic work value. Roberts and colleagues (2003) also found a high degree of consistency between selection and socialization effects. For example, negative emotionality at age 18 was found to be associated with financial insecurity at age 26 , an environmental feature that was also associated with further increases in negative emotionality between 18 and 26. Similarly, Hudson et al. (2012) found corresponding changes between agreeableness and social investments in work.

\section{The Current Study}

The present study set out to investigate person-environment transactions within the occupational context. As described above, previous studies have demonstrated selection, socialization, and attrition transactions between personality traits and job characteristics. Some studies have interpreted a similarity between vectors of selection and socialization effects as being consistent with a "corresponsive principle of personality development" (Roberts et al., 2003). However, the evidence in favor of this principle is limited by a number of factors. First, studies investigating personality development have typically focused on subjective assessments of environmental features, which can produce spurious results when people adjust perceptions of the environment to be more consistent with their personality (Harms et al., 2006). Second, studies using a longitudinal design are relatively rare, and when they are conducted, they typically do not employ a full cross-lagged design (for an exception, see Sutin \& Costa, 2010). Third, studies typically focus on either selection processes within samples of job beginners (e.g., college graduates), consistency in job stayers, or intentions of job changers - but never have these groups been studied within one framework that would allow painting a more thorough picture of person-environment transactions within the occupational domain. Especially studies on person-environment fit increases in job changers are extremely rare and have thus far only explored comparisons between current and imagined future professions (Donohue, 2006; Oleski \& Subich, 1996). Finally, there are only a handful 
of studies on this topic and most of these have been conducted in the US or other englishspeaking countries, which limits the generalizability of conclusions.

By investigating a large and heterogeneous sample including job beginners, job stayers, and actual job changers drawn from a larger nation-wide study in Germany, the present study addressed some of the methodological limitations of previous research. A full cross-lagged design was employed to compare the relative influence of active selection effects and passive socialization effects within the sample of job changers. The precision of this comparison was increased by focusing on environmental features (namely occupational role demands) that directly map onto the traits they are supposed to influence. Therefore, the inference of an underlying mechanism that binds personality with a specific job characteristic (e.g., inferring that occupational power is conducive of positive emotionality and therefore should be related to extraversion) was not necessary. In addition, investigating associations between personality and trait-specific job characteristics limits the number of significance tests and thus capitalization on chance when compared to a more exploratory approach that crosses a more comprehensive set of environmental characteristics with a comprehensive set of personality traits. The present study relied on externally rated role demands (based on vocational codes), which allows a more stringent test of socialization effects when compared to self-rated demands that may be affected by bias such as cognitive dissonance. This also allowed us to study the heterotypic continuity of environmental features, as operationalized by the consistency in normative demands even when selecting oneself into a different vocation.

\section{Method}

\section{Participants}

Results are based on data of the German Socio-Economic Panel Study (SOEP). The SOEP contains an ongoing longitudinal and heterogenous large-scale assessment of private households in Germany since 1984 (Wagner et al., 2007). Information was gathered through interviews or via questionnaires from a total of 21,105 individuals in 2005 and 20,869 
participants in 2009. For the subsequent analyses, a subsample of employees was formed by excluding participants who were not employed in 2005 or 2009 and thus did not have occupation codes for either or both time points. This reduced the sample to 7,080 participants. Furthermore, we excluded participants older than 67 years of age in 2009, because they exceeded the legal retirement age in Germany. The sample finally reached a size of 6,991 employed persons ( $46.3 \%$ women) for whom relevant information regarding personality traits, occupational data, age and gender was available for the two time points. The present analyses are based on the following three subsets of participants.

Job beginners. The first sample was part of an added "youth sample" of the SOEP (i.e., not part of the base sample described above). It included 640 individuals who were identified in the SOEP as having started a job (this information is included in a separate variable of the dataset) at the same time or after their first personality measure. Of these individuals, the first personality assessment took place in 2005 for 300 participants, in 2006 for 109 participants, in 2007 for 94 participants, in 2008 for 66 participants, and in 2009 for 71 participants (samples in 2006-2009 were part of a special youth assessment of the SOEP, which is why sample sizes are lower than in 2005, which was a regular assessment year). These participants filled out the personality questionnaires in the year they turned 18 and provided information about their vocational situation in 2009. The first job of the participants started in 2005 for 75 participants, 2006 for 64 participants, 2007 for 96 participants, 2008 for 93 participants, and 2009 for 219 participants. In 2009, the mean age of this sample was 21.24 years $(S D=2.83$, range: $18-30$ years $)$, it consisted of $50 \%$ women.

Job stayers. This subsample was formed by selecting all individuals with a vocational code in 2005 that did not change in 2009 . The sample finally reached a size of 4,137 employed persons (49.1\% women) for whom information regarding personality traits and occupation was available for the two time points. The mean age in 2009 was 46.63 years ( $S D$ 
$=9.86)$ and ranged from 21 to 67 years. Participants were mainly employed full-time (2005: 73.2\% and 2009: 73.9\%) or regular part-time (2005: 19.6\% and 2009: 20.1\%).

Job changers. Job changers were identified by a change in occupation code within the four-year interval. The sample finally reached a size of 2,854 employed persons $(42.4 \%$ women) for whom information regarding personality traits and occupation was available for the two time points. The mean age in 2009 was 44.68 years $(S D=10.44)$ and ranged from 21 to 67 years. Participants were mainly full-time (2005: 72.3\% and 2009: 75.7\%) or regular part-time employed (2005: 15.5\% and 2009: 16.1\%).

Before transactions are compared between job stayers and job changers, it was first tested whether both groups were comparable. Therefore we tested whether the two groups differed from the beginning in terms of age, gender, years and intensity of participation in the labour market, personality and job demands. The group of changers consisted of more male participants than did the group of stayers, $58 \%$ vs. $51 \%, \chi^{2}(1)=30.29, p<.001$. They were considerably younger, $t(5901.31)=7.86, p<.001$, and had a shorter history of participation in the labor market, $t(5898.52)=6.28, p<.001$. The groups did not differ in their proportion of employed full-time participants, $\chi^{2}(1)=.61, p=$ ns. Regarding personality, both groups did not differ on self-reported Big Five dimensions, but changers generally possessed jobs with lower personality role demands, $t(6298.84-6760.36)=2.09-11.55, p<.001-.05$.

\section{Measures}

Big Five. The two waves of the SOEP in 2005 and 2009 contained the BFI-S (Dehne \& Schupp, 2007; Gerlitz \& Schupp, 2005), a short version of the German Big Five Inventory (Lang, Lüdtke, \& Asendorpf, 2001). The instrument measures the Big Five personality traits (extraversion, agreeableness, conscientiousness, emotional stability, and openness) with three items for each dimension. Participants rated their agreement on a scale ranging from 1 ("does not apply to me at all”) to 7 (“applies to me perfectly"). Examples of items are: "I see myself 
as someone who worries a lot" (emotional stability; reversed item), "I see myself as someone who is reserved" (extraversion, reversed item) or "I see myself as someone who has an active imagination" (openness; Gerlitz \& Schupp, 2005; John \& Srivastava, 1999). We reversed the responses to the neuroticism items to capture emotional stability before including them in subsequent analysis. Internal consistencies ranged from $\alpha=.51$ to .66 (see Table 1).

Comparable consistency values of the BFI-S have been reported elsewhere in papers based on the SOEP (Dehne \& Schupp, 2007) and are a natural result of the need for scale brevity in large-scale panel studies, such as the SOEP (Denissen, Geenen, Selfhout, \& van Aken, 2008). The use of structural equation modeling allowed the estimation of paths that are corrected for unreliability.

Coding of personality role demands. The four-digit ISCO-88 occupation code (International Standard Classification of Occupations; Hoffmeyer-Zlotnik \& Geis, 2003) that is included in the SOEP dataset served as source of information about participants' occupation. The codes allow for the differentiation between 457 occupations. In 2005, 281 of these professions were represented in the sample, versus 285 in 2009. The following two sets of raters were used, who evaluated the occupations twice with regard to their relation to the aforementioned poles of the Big Five factors extraversion, agreeableness, conscientiousness, emotional stability, and openness (raters were provided with the facet labels of the NEO-PI-R to semantically calibrate the reference categories).

Student ratings. Ten independent raters estimated a) the importance of each Big Five factor for a good job performance $(0=$ "not important", 1 = "important", 2 = "very important") and $b)$ the prototypicality of each trait for a representative of the corresponding profession ( 0 = "not typical", 1 = "typical", 2 = "very typical"). Raters were graduate students of psychology or linguistics, who were familiar with descriptions of the Big Five personality dimensions in the scientific literature. The ratings of importance and typicality were highly correlated, with an average correlation of .65 within raters. We thus averaged across the two 
indicators. Furthermore, we aggregated across the 10 raters and thus obtained highly reliable composites $(\alpha=.85-.92$; see Table 2$)$.

Expert ratings. We secured the collaboration of the German Federal Employment Agency, which enabled four vocational experts to take part in our study. All 176 professions with at least 10 representatives in the sample were rated during a consensual group discussion. Due to time constraints, the experts only rated the importance of traits for successful job enactment. As shown in Table 2, reliability of the ratings of 25 independently coded professions was excellent, with the exception of the reliability of conscientiousness role demands, which was much poorer (alpha $=.25)$ compared to the agreement for the other traits (alpha between .87 and .94).

\section{Analytic Strategy}

We tested the hypotheses with a series of structural equation models (implemented in $\mathrm{R}$ with the lavaan package, Version 0.4-9; Rosseel, 2010). These models modeled both personality traits and personality role demands as latent variables. In the case of personality, the three items of each scale were used as manifest indicators, whereas three parcels (consisting of three to four raters) were generated as manifest indicators of the latent role demand variables. We constructed models with strict factorial invariance in terms of equal factor loadings, measurement intercepts, and error variances across time points (Meredith, 1993). Residuals were allowed to be correlated between time points to make sure that effects were due to the factors of interest instead of specific item contents (Bollen \& Curran, 2006). In summarizing the results of the analyses, standardized regression coefficients will be reported.

For job beginners, latent models essentially included a stability path between both measures of personality, as well as a selection path linking pre-2009 personality with personality role demands in 2009 . For job stayers, a model was estimated that included a stability path between 2005 and 2009 personality, in addition to a socialization path flowing 
from 2005 role demands to rank-order personality changes between 2005 and 2009. Finally, for job changers, a full latent cross-lagged model was implemented, with stability paths for both personality and role demands and two cross-lagged paths: from personality in 2005 to rank-order changes in role demands between 2005 and 2009, and between role demands in 2005 and rank-order changes in personality between 2005 and 2009. To ensure the robustness of the results against possible violations of statistical assumptions, all analyses were repeated using bootstrapping, which produced highly similar results.

\section{Results}

\section{Descriptives of Personality Role Demands}

Convergence between two rating sources. Convergent correlations between the student ratings and the expert ratings indicated a large degree of convergence, with correlations ranging between .72 and $.78, \mathrm{p}<.01$. Only the convergence for conscientiousness was weaker, $r=.52$, again reflecting the problematic nature of rating this personality role demand.

Mean role demand levels. Table 2 shows that the mean of the demand ratings for occupations varied across the Big Five dimensions. Across both sets of raters, high levels of conscientiousness were more regularly demanded in occupations than high levels of the other Big Five traits. Examples of jobs with high levels of coded role demands include "film, stage, related actor, director" (high extraversion demand), "religious professional" (high agreeableness demand), "police officer" (high conscientiousness demand), "judge” (high emotional stability demand), and "composer, musician, singer" (high openness demand). Examples of jobs with low levels of coded role demands include "forestry worker, logger" (low extraversion demand), "computer systems designer, analyst" (low agreeableness demand), "garbage collector" (low conscientiousness demand), "telephone installer, servicer" (low emotional stability demand), and "transport laborer, freight handler" (low openness demand). 
Actual personality levels. We computed the average personality role demand level for each included occupation. To avoid unreliable estimates, this was done only for ISCO-88 classified occupations with at least 25 members in $2005(n=9,757$ accounting for $87 \%$ of all employed participants of the 2005 wave and $30 \%$ of the classified jobs by the ISCO system). Intercept reliabilities of these aggregates (calculated using linear mixed effect models with vocational code as grouping variable; see Raudenbush \& Bryk, 2002) averaged across waves were .65 for extraversion, .64 for agreeableness, .52 for conscientiousness, .61 for emotional stability, and .83 for openness. Results thus indicate that representatives of different professions, seen as a collective, are reliably different from each other in terms of openness, whereas such generalizations are somewhat less reliable for the other Big Five dimensions, especially for conscientiousness.

Kernel of truth. It was checked whether the ratings of personality role demands have a kernel of truth by correlating them with the aggregate of all Big Five self-reports across vocations. For example, a high kernel of truth correlation would indicate that occupations that score high on a particular personality norm demand are also carried out by people who actually score high on the corresponding trait. Table 2 shows especially high "kernel of truth correlations" for openness to experience and extraversion, followed by agreeableness. For emotional stability, only the kernel of truth correlation of the student ratings was significant. Across both sets of raters, ratings tapping into the conscientiousness role demand of professions were slightly negatively correlated with empirical values of people working in these professions. Because these role demands could apparently not be reliably rated by our judges (see discussion section for possible reasons), this trait was not considered further in subsequent analyses.

Associations with age. Finally, we checked whether role demands were associated with age. For the student ratings, we found that age was positively associated with personality role demands in conscientiousness and emotional stability in all three groups, with scattered 
effects found for extraversion and openness as well (e.g., age was associated with an increase in openness role demands in beginners and changers, but not in changers). Importantly, controlling for age did not change the pattern of results reported below. For the expert ratings, no significant correlations with age were found.

\section{Models For Job Beginners}

For the student ratings, the models for assessing the fit between initial personality and the personality role demands of the first occupation had an excellent fit in all cases $(16.44 \leq$ $\left.\chi^{2} \leq 43.42, d f=26, \mathrm{CFI} \geq .99, \mathrm{RMSEA} \leq .03\right)$. Resulting paths can be obtained from the lefthand panels of Figure 1 (coefficients left of the slash). As can be seen, personality stability in beginners was substantial (ranging between .53 and .73 ). Controlling for this stability, the correlation between Time 2 job characteristics and personality changes between Time 1 and 2 was significant for extraversion. Most importantly, significant selection paths from personality to role demand were obtained for extraversion, agreeableness, and openness. In contrast, Time 1 emotional stability was not associated with selecting of congruent role demands at Time 2 in job beginners.

For the expert ratings, fit indices were highly satisfactory $(13.58 \leq \chi 2 \leq 20.22, \mathrm{df}=14$, $\mathrm{CFI} \geq .99, \mathrm{RMSEA} \leq .03$ ). As can be seen in Figure 1 (coefficients right of the slash), results that were significant with the student raters were replicated, with somewhat attenuated coefficients. That is, selection paths were replicated for extraversion, agreeableness, and openness, as was the path between Time 2 job characteristics and extraversion. Furthermore, an additional significant path was obtained between Time 2 job characteristics and agreeableness.

\section{Models For Job Stayers}

Model fit was excellent for the models of job stayers, $87.49 \leq \chi^{2} \leq 217.20, d f=26$, CFI $\geq .99$, RMSEA $\leq .04$. As can be seen in Figure 1, the latent stability of personality was relatively high but by no means perfect, ranging between .73 and .78 . A significant amount of 
Time 1 congruence between personality and role demands was found in the case of extraversion, agreeableness, and openness, with standardized coefficients between .15 and 19 . Most importantly, socialization effects were statistically significant for extraversion, agreeableness, and openness.

For the job stayers, model fit for the expert models was again excellent, $49.63 \leq \chi^{2} \leq$ 78.03, $\mathrm{df}=14, \mathrm{CFI}=.99, \mathrm{RMSEA} \leq .03$. All Time 1 congruence coefficients that were significant in the models based on the student ratings were replicated. In addition, the socialization effects for extraversion and openness were replicated, but not the selection effect for agreeableness.

\section{Models For Job Changers}

Fit indices for the job changers models based on the student ratings were excellent in all cases, $100.99 \leq \chi 2 \leq 230.41, d f=52, \mathrm{CFI} \geq .99, \mathrm{RMSEA} \leq .04$. Turning to the different paths (shown in the right-hand Panels of Figure 1), the stability of personality was slightly lower than found for job stayers (the difference was statistically significant in the case of openness and agreeableness, though the absolute size of the difference was rather small). Compared to job stayers, similar concurrent congruence between personality and personality role demands was found, with significant associations found for extraversion, agreeableness, and openness. The stability of role demands (i.e., similar psychological environment despite occupational changes) was statistically significant in all cases, indicating substantial heterotypic continuity. The highest estimate was found for agreeableness role demands (.57), whereas the other heterotypic continuity estimates hovered around .40 .

Socialization effects were also investigated. For the job changers, significant socialization effects would mean that the previous vocation (or associated contextual features, which might be stable after quitting the job) still exerts an influence on rank-order changes in personality. Such a "delayed effect" was found for openness and agreeableness. Turning to selection effects, significant paths were found for extraversion, emotional stability, and 
openness. Especially the latter effect was the largest cross-lagged effect of the present study. No selection effects were found for agreeableness. To test in which cases the socialization and selection effects differed significantly, the change in fit when they were constrained to be equal was calculated. In the case of openness and agreeableness, the difference turned out to be statistically significant, suggesting that selection effects were more important for the former, and socialization effects for the latter. Finally, correlated 2009 residuals were tested and reached statistical significance in the case of agreeableness and openness to experience. This effect suggest that a rank-order increase in these traits was accompanied by a rank-order increase in corresponding role demands (independent of predictors from 2005).

For the models based on the expert ratings, fit indices were excellent, $24.10 \leq \chi^{2} \leq$ 45.97, $d f=18, \mathrm{CFI} \geq .99, \mathrm{RMSEA} \leq .03$. As can be seen in Figure 1 , all Time 1 congruence paths that were significant when testing the models based on the student ratings were replicated, albeit with attenuated coefficients. The same was true for the coefficients indicating heterotypic continuity, with the highest estimates found for agreeableness (.36) and emotional stability (.35) role demands. In addition, all "delayed" socialization effects based on the student ratings were replicated, as well as two out of three selection effects. Specifically, extraversion and openness were associated with rank-order increases in corresponding role demands as rated by experts, but this was not the case for emotional stability. Finally, the correlated change effect that was found for openness based on the student ratings was replicated, but not the correlated change effect for agreeableness.

\section{Additional Analyses}

We conducted moderator analyses (using multi-group comparison in lavaan) to see if effects differed according to age. Only job stayers and changers were considered because the sample of job beginners was too homogeneous in age. The sample was split into two age groups of about equal size (21-44 vs. 45-67). We also explored more fine-grained age distinctions by dividing the samples of stayers and changers into four age quantiles of more or 
less equal size. Two consistent results emerged from these analyses. First, for changers, the four-quantile analyses for both the student ratings and the expert ratings pointed out that the rank-order stability of emotional stability is higher in midlife than both younger and older age periods, thus replicating a finding by Specht et al. (2011) using a similar sample of the SOEP. Second, across different analyses, results indicated that older individuals have a higher level of heterotypic stability than younger individuals. Specifically, this pattern was found when using both student ratings and expert ratings in the case of agreeableness (when focusing on the 2-level and 4-level age variable in the case of the student ratings and the 4-level age variable in the case of the expert ratings). In the case of emotional stability, the pattern was found for the student ratings when focusing on the 4-level age variable and the expert ratings when focusing on the 2-level variable. Finally, in the case of extraversion the pattern was confirmed when focusing on the 4-level age variable in the case of the expert ratings.

\section{Multivariate Effects}

As can be seen in Table 2, the rated personality role demands were not independent from each other. This raises the question whether results are indicative of trait-specific environmental influences, or whether they reflect more general influences (i.e., akin to a "general factor" of personality roles demands). To explore possible redundancies, additional models were constructed for each trait, with loadings from all trait-specific role demands onto an overarching general factor of personality role demands. This general factor was then included as predictor of personality and a covariate of trait-specific role demands. The fit of these complex models was acceptable to good in all cases $($ RMSEA $<.11$, CFI $>.87)$, except for agreeableness role demands as rated by experts, which had to be excluded from the general factor due to problems with collinearity $(\mathrm{RMSEA}=.18, \mathrm{CFI}=.52)$.

Results generally provided support for the robustness of the role demand effects. For the models based on the student ratings, 23 out of 32 effects were replicated (in terms of 
statistical significance: yes/no). For the models based on the expert ratings, this was the case 20 out of 32 effects. The majority of non-replicated effects concerned trait-specific effects that were initially significant, but in some cases new effects also became significant after controlling for the general factor. In the former case, the job demand effect that was initially significant was replaced by a corresponding general factor effect in at least 5 out of 6 (student ratings) and 4 out of 8 (expert ratings) cases. Overall, in spite of some overlap, the majority of effects thus emerged as robust after controlling for generalized role demands. An interesting pattern was found for the heterotypic continuity estimates of the job changers. On average, the heterotypic continuity of the general factor (average $r=.40$ ) was comparable to that of the trait-specific role demands (average $r=.43$ ) in the case of the student ratings. When based on the expert ratings, however, the heterotypic continuity of the trait-specific role demands decreased substantially (to an average $r=.14$ ) though it remained statistically significant in all cases.

\section{Discussion}

The present study focused on occupational socialization and selection in a sample of job beginners, stayers, and changers and resulted in three main findings. First, we found a significant amount of congruence between occupational norm demands and the personality traits of corresponding professionals. Second, we found a substantial degree of longitudinal continuity in role demands, even when individuals change jobs. Finally, for three out of four traits, evidence for corresponsive patterns was found. In the following, we will discuss our findings in more detail.

\section{Personality Role Demands}

One of the main goals of the present paper was to use a novel method of measuring personality role demands as environmental factors that are transactionally related to personality change. Because both personality and personality role demands pertained to the same trait domain in our study (e.g., extraversion), such a comparison is more focused than 
comparing transactions between personality and other environmental features (e.g., stress or income). To the best of our knowledge, the present study is the first to empirically test the effects of role demands in a longitudinal study of personality development. Role demands are central in theories of personality development that stress socialization processes, such as investment in social roles (Roberts et al., 2005). They also feature prominently in accounts of professional socialization: the idea that people's personality comes to resemble the vocation in which they are active (du Toit, 1995). We operationalized role demands having independent observers rate different professions regarding the typicality of and need for high levels of the Big Five personality traits.

Results indicated that for most traits, our measure of role demand performed well. There was high agreement between raters regarding differences in personality role demands between different professions, and there was substantial congruence between ratings of importance and typicality. These differences were not only face valid but also converged substantially with aggregated values of actual professionals, especially in the case of extraversion, agreeableness, and openness to experience. Even across individuals who changed their occupation, the underlying psychological characteristics of the environment were moderately stable (see Table 2), constituting a potentially powerful source of individual differences.

One interesting question pertains to the measurement of personality role demands. In our study, we used both student ratings and vocational expert ratings. In general, results were similar in terms of the overall pattern, although in some cases effects were suppressed when expert ratings were used. The latter finding can be attributed to the latent modeling of the student ratings, which allowed the structural equation models to disattenuate path coefficients, which was not possible for the expert ratings because these were based on consensus. The fact that student ratings held up so well in terms of replicability is remarkable because they did not have specialized knowledge of job demands. This might suggest that even the students had 
sufficient basic knowledge of a basic set of widely-held occupations. Furthermore, it might be that students relied on stereotypes. We think that these explanations are not mutually exclusive because student ratings had a substantial kernel of truth, as evidenced by the convergent correlations with actual job representatives' self-rated personality scores. This suggests that future studies might rely on non-expert ratings to uncover transactions between role demands and personality development, although ideally both sets of raters are available for cross-validation (as was done in our study).

\section{Selection and Socialization Effects}

Robust selection effects were found for both job beginners and job changers. In job beginners, initial levels of extraversion, agreeableness, and openness were prospectively associated with personality role demands of first jobs. Similarly, in job changers, extraversion and openness (and emotional stability, in models based on student ratings) were associated with trait-consistent rank-order changes in personality role demands. In other words, after switching their occupation, these individuals were statistically likely to end up in a new job that is more congruent with their personality than their old job. As stated in the introduction, these selection effects may reflect an active process of niche selection in which individuals select environments that maximize the adaptive outcomes of their personality configuration.

Such outcomes may be anticipated by (consciously or unconsciously) assessing the degree of fit between one's personality traits and the corresponding personality role demands of an occupation. If individuals follow up on this assessment and select themselves into traitcongruent environments, this constitutes an impressive example of active niche selection of the kind that transactional theorists have long talked about (Buss, 1987; Scarr \& McCartney, 1983).

The present findings are also consistent with theoretical accounts that stress socialization effects flowing from social environments to accommodating personality changes (Harms et al., 2006). Specifically, the personalities of job stayers in occupations with role 
demands for high extraversion and openness to experience (and agreeableness, in models based on student ratings) were found to become increasingly accommodating to these demands. This is consistent with the phenomenon of déformation professionelle, which has been described as a process of occupational acculturation by which the identification of professional norms set into motion a process of corresponding personality change (du Toit, 1995). The present study is the first to demonstrate this phenomenon for a broad range of professions, focusing on the Big Five personality traits.

\section{Differences Between Traits}

Notwithstanding these generalizations, there were stark differences between traits in terms of norm demand measurement and person-environment transactions. It is useful to contrast conscientiousness and openness to experience in this regard. Beginning with the former, ratings of personality role demand were somewhat less internally consistent across raters. Mean levels of rated demands were much higher than those found for other traits (see Table 2), which probably relates to the fact that conscientiousness is an important trait across a wide range of professions (Judge, Heller, \& Mount, 2002; Ones, Viswesvaran, \& Schmidt, 1993). Perhaps as a result, representatives of different professional groups could not be reliably described and distinguished in terms of their mean conscientiousness values (as indicated by lower intercept reliabilities). A closer inspection of the examples provided in the method section suggests that raters may rely upon salient but invalid cues associated with more peripheral job characteristics. For example, the attribution of low conscientiousness to the work of a garbage collector seems more superficially based on salient features of this profession's work environment (untidy) than on an analysis of the actual job description (tidying things up) or work patterns (importance of collecting the trash on time).

This stands in stark contrast to openness to experience. Rating agreement was highest for this trait, and average levels of rated role demand were neither inflated nor restricted in range. Intercept reliability reached a level that is comparable with proper questionnaire scales, 
indicating that there is a fair degree of homogeneity among the representatives of different professions. This is strongly reminiscent of McCrae's (1996) observation that open- and closed-minded people gravitate towards different professions and social niches. Indeed, external raters seemed able to pick up on these existing differences between different types of professions, as evinced by the impressive "kernel of truth correlation" between rated norm demand and empirically observed openness levels. These consistent and salient role demands likely facilitated consistent transactional effects that were found for this trait. For example, the fact that individuals were better able to accurately assess the openness role demands of various professions probably facilitated the selection of an occupational niche that is consistent with their openness levels. Moreover, the greater degree of professional homogeneity likely facilitates peer socialization, which would explain the pattern of occupational socialization that was demonstrated for both job stayers and changers.

One pattern that emerged in the data is that selection effects were only significant in both beginners and stayers in the case of extraversion and openness to experience (effects for agreeableness and emotional stability were less robust across raters and samples). This is consistent with these traits' loading on the higher-order beta factor of personality (Digman, 1997). This factor taps into more pro-active and agentic aspects of personality. In the case of extraversion, this pro-activeness is related to the establishment of social relationships, whereas for openness it related more to the exploration of novelty (e.g., the trait has been associated with migration movements by Camperio Ciani, Capiluppi, Veronese, \& Sartori, 2007). Both traits may thus be associated with more vigorous niche selection, reflected in the more robust trait-congruent selection effects when establishing or changing a career. More research is needed to further explore this line of thinking, however.

\section{Corresponsive Changes}

According to the so-called corresponsive principle of personality development, the traits that select people into certain niches are deepened as a result of exposure to this niche. 
Some support for this principle was found in the current study: In the case of extraversion, personality role demands of beginners' first job were indeed associated with their personality before the transition into paid employment as well as corresponding personality changes during this transition. Because this correspondence in job beginners does not allow an assessment of whether personality predicts changes in job characteristics (because these are measured only once), a second test of the corresponsive principle was also conducted: Whether socializing effects in job stayers mirror the selection effects in job changers. Results for the trait of extraversion were consistent with this principle, as were results for openness. Finally, one could argue that the results for agreeableness were also consistent with the corresponsive principle, as selection effects in job beginners were followed by socialization effects in job stayers (only in models based on student ratings) and even in job changers. This pattern of findings underscores the importance of the corresponsive principle as a transactional mechanism promoting cumulative personality stability (which is also consistent with the slightly higher personality stability of job stayers when compared to job changers).

\section{Strengths and Limitations of the Present Study}

As described above, there are a number of substantial strengths that make the present study unique in its contribution to the study of person-environment transactions. First, it is a longitudinal study with beginners, stayers, and changers that has a sample size that is substantially large to include a broad range of occupations. In addition, the present study also avoided a reliance on self-reports in the assessment of vocational role demands, which rules out the possibility that assessments of the environment are assimilated to match perceptions of current needs (Harms et al., 2006). Furthermore, it included job beginner, job stayer, and job changers from a variety of ages and was thus able to study various kinds of personenvironment transactions that would not have been possible when focusing only on one group of individuals. Especially our sample of job changers offered unique opportunities in this regard because it allowed us to control for heterotypic norm continuity and study correlates of 
actual job changes instead of merely intended ones (as was done in previous studies; Donohue, 2006; Oleski \& Subich, 1996).

Of course, the present study also suffered from some limitations. To begin with, a change in job characteristics required a change of vocation. Whereas such vocational change likely represents a profound environmental change, it is also possible to change the characteristics of one's daily work environment without changing one's vocation. Indeed, there might be dimensions of structural job affordances that underlie personality roles demands (Raymark, Schmit, \& Guion, 1997). For example, the amount of customer contact might be one of the determinants of extraversion role demands. Future studies might code such determinants as possible origins of personality role demands. Furthermore, it was not possible to distinguish the influence of applicants' attraction from organizations' assessment procedures in interpreting selection effects. For example, it is theoretically possible that the fit between beginners' and changers' personality and their eventual occupations resulted from organizations weeding out applicants with non-matching personalities (thus assigning a more passive role to these applicants themselves). Future studies assessing applicants' vocational ambitions before and after they are tested by organizations' HR departments are needed to separate the two.

Another set of limitations follows from the measures used in the present study. To begin, it would have been preferable to include more comprehensive measures of personality traits, including scales with more items and covering a broader range of facets and/or traits. Regarding role demands, future studies may include additional sources of information. For example, structured interviews with experienced workers within different vocational fields may be conducted. In addition, it may be worthwhile to compare outsiders' ratings of environmental characteristics with more proximal subjective ratings by individuals themselves. The idea that people might to a certain degree "craft" their jobs in terms of the personality role demands that are necessary on a moment-to-moment basis could inspire novel 
studies that uses more fine-grained designs, such as experience sampling. Future studies could focus on a broader range of time resolutions, so that short-term micro-longitudinal processes are investigated as antecedents and outcomes of person-environment transactions. More specifically, a study could track employees in their daily work life and assess their day-to-day perceptions of role demands as well as specific work activities and test if these predict fluctuations in personality states. On a longer-term timeframe, participants could be asked to describe their expectations regarding various job-related personality role demands and test how these perceptions predict actual choices.

Finally, it may be argued that effects were relatively small. For a number of reasons, we do not believe that this diminishes their importance, however. First, the cross-lagged coefficients represent effects over a period of four years, controlling for the stability of the target variables. Such effects are typically not very strong, given that there is only limited variance that remains after controlling for stability, and some initial effects may be washed out by subsequent noise. Second, when corresponsive changes are found, effects can cumulate over time. Specifically, when initially weaker transactional effects reinforce each other (Neyer \& Asendorpf, 2001), they may produce a substantial degree of fit between persons and environments. Direct evidence for this was found in the present study. These effects can account for kernel of truth correlations (fit between personality role demands and personality profiles at the aggregate level of entire occupations) of up to .71. As such, they have important implications for understanding the psychological processes that might underlie labor market specialization.

\section{Conclusion}

The present study employed a novel approach to sample norm demands that relate to personality traits. A major strength of this methodology is that role demands are assessed indirectly, without being conflated with self-reported personality or individual biases. Results provided first insights into the fascinating developmental interplay between both systems. For 
example, it was shown that personality norm demands display a substantial amount of heterotypic continuity, even when people change their outward vocation. In addition, our method allowed for a comparison of the strength of selection effects and socialization effects in job stayers and changers. Results indicate that selection effects are somewhat stronger than socialization effects in some but not all cases. These overall conclusions varied between different personality traits, however, and more longitudinal studies into the developmental interplay of roles and personality are clearly necessary to complete this emerging picture. Such future studies will hopefully shed even more light on transactions between individuals and social roles, which are at the forefront of highly influential theories such as Social Investment Theory (Roberts et al., 2005). 


\section{References}

Ackerman, P. L. (1996). A theory of adult intellectual development: Process, personality, interests, and knowledge. Intelligence, 22, 227-257.

Asendorpf, J. B., \& van Aken, M. A. (2003). Personality-relationship transaction in adolescence: Core versus surface personality characteristics. Journal of Personality, $71,629-666$.

Assouline, M., \& Meir, E. I. (1987). Meta-analysis of the relationship between congruence and well-being measures. Journal of Vocational Behavior, 31, 319-332. doi:10.1016/0001-8791(87)90046-7

Baltes, P. B. (1987). Theoretical propositions of life-span developmental psychology: On the dynamics between growth and decline. Developmental psychology, 23, 611-626. doi:10.1037/0012-1649.23.5.611

Bollen, K., \& Curran, P. (2006). Latent Curve Models: A Structural Equation Perspective. Hoboken: Wiley.

Buss, D. M. (1987). Selection, evocation, and manipulation. Journal of Personality and Social Psychology, 53, 1214-1221. doi:10.1037/0022-3514.53.6.1214

Camperio Ciani, A. S., Capiluppi, C., Veronese, A., \& Sartori, G. (2007). The adaptive value of personality differences revealed by small island population dynamics. European Journal of Personality, 21, 3-22. doi:10.1002/per.595

Cartwright, L. K., \& Wink, P. (1994). Personality change in women physicians from medical student years to mid 40s. Psychology of Women Quarterly, 18, 291-308. doi:10.1111/j.1471-6402.1994.tb00456.x

Cooper-Thomas, H. D., van Vianen, A., \& Anderson, N. (2004). Changes in person organization fit: The impact of socialization tactics on perceived and actual $\mathrm{P}-\mathrm{O}$ fit. European Journal of Work and Organizational Psychology, 13, 52-78. doi: $10.1080 / 13594320344000246$

Dehne, M., \& Schupp, J. (2007). Persönlichkeitsmerkmale im Sozio-okonomischen Panel (SOEP) - Konzept, Umsetzung und empirische Eigenschaften. Research Notes 200726. Berlin: DIW. 
Denissen, J. J. A., Geenen, R., Selfhout, M., \& van Aken, M. A. G. (2008). Single-item big five ratings in a social network design. European Journal of Personality, 22, 37.

Digman, J. M. (1997). Higher-order factors of the Big Five. Journal of Personality and Social Psychology, 73, 1246-1256.

Donohue, R. (2006). Person-environment congruence in relation to career change and career persistence. Journal of Vocational Behavior, 68, 504-515. doi:10.1016/j.jvb.2005.11.002

du Toit, D. (1995). A sociological analysis of the extent and influence of professional socialization on the development of a nursing identity among nursing students at two universities in Brisbane, Australia. Journal of Advanced Nursing, 21, 164-171.

Eccles, J. S. (1994). Understanding women's educational and occupational choices. Psychology of Women Quarterly, 18, 585-609. doi:10.1111/j.14716402.1994.tb01049.x

Edwards, J. R., Cable, D. M., Williamson, I. O., Lambert, L. S., \& Shipp, A. J. (2006). The phenomenology of fit: Linking the person and environment to the subjective experience of person-environment fit. Journal of Applied Psychology, 91, 802-827. doi:10.1037/0021-9010.91.4.802

Ehrhart, K. H., \& Makransky, G. (2007). Testing vocational interests and personality as predictors of person-vocation and person-job fit. Journal of Career Assessment, 15, 206-226. doi: 10.1177/1069072706298105

Eli, I., \& Shuval, J. T. (1982). Professional socialization in dentistry: A longitudinal analysis of attitude changes among dental students towards the dental profession. Social Science \& Medicine, 16, 951-955. doi:10.1016/0277-9536(82)90362-8

Fraley, C. R., \& Roberts, B. W. (2005). Patterns of continuity: A dynamic model for conceptualizing the stability of individual differences in psychological constructs across the life course. Psychological Review, 112, 60-74. doi:10.1037/0033295X.112.1.60 
George, L. G., Helson, R., \& John, O. P. (2011). The “CEO” of women's work lives: How Big Five Conscientiousness, Extraversion, and Openness predict 50 years of work experiences in a changing sociocultural context. Journal of Personality and Social Psychology, 101, 812-830. doi:10.1037/a0024290

Gerlitz, J.-Y., \& Schupp, J. (2005). Zur Erhebung der Big-Five-basierten Persönlichkeitsmerkmale im SOEP, DIW Research Notes 2005-4. Berlin: DIW.

Harms, P. D., Roberts, B. W., \& Winter, D. (2006). Becoming the Harvard man: Personenvironment fit, personality development, and academic success. Personality and Social Psychology Bulletin, 32, 851 -865. doi:10.1177/0146167206287720

Hoffmeyer-Zlotnik, J. H. P., \& Geis, A. J. (2003). Berufsklassifikation und Messung des beruflichen Status/Prestige. ZUMA-Nachrichten, 27, 125-138.

Holland, J. L. (1959). A theory of vocational choice. Journal of Counseling Psychology, 6, 35-45. doi:10.1037/h0040767

Holland, J. L. (1987). Some speculation about the investigation of person-environment transactions. Journal of Vocational Behavior, 31, 337-340. doi:10.1016/00018791(87)90048-0

Holland, J. L., \& Nichols, R. C. (1964). Explorations of a theory of vocational choice: III. A longitudinal study of change in major field of study. The Personnel and Guidance Journal, 43, 235-242. doi:10.1002/j.2164-4918.1964.tb02667.x

Hudson, N. W., Roberts, B. W., \& Lodi-Smith, J. (2012). Personality trait development and social investment in work. Journal of Research in Personality, 46, 334-344. doi:10.1016/j.jrp.2012.03.002

Hurtz, G. M., \& Donovan, J. J. (2000). Personality and job performance: The Big Five revisited. Journal of Applied Psychology, 85(6), 869-879. doi: 10.1037/00219010.85 .6 .869

John, O. P., \& Srivastava, S. (1999). The Big-Five trait taxonomy: History, measurement, and theoretical perspectives. In L. A. Pervin \& O. P. John (Eds.), Handbook of personality: Theory and research (Vol. 2, pp. 102-138). New York: Guilford Press. 
Judge, T. A., Heller, D., \& Mount, M. K. (2002). Five-factor model of personality and job satisfaction: A meta-analysis. Journal of Applied Psychology;Journal of Applied Psychology, 87, 530-541. doi:10.1037/0021-9010.87.3.530

Kanfer, R., Wanberg, C. R., \& Kantrowitz, T. M. (2001). Job search and employment: A personality-motivational analysis and meta-analytic review. Journal of Applied Psychology, 86, 837-855. doi:10.1037/0021-9010.86.5.837

Kristof-Brown, A. L., Zimmerman, R. D., \& Johnson, E. C. (2005). Consequences of individuals' fit at work: A meta analysis of person-job, person-organization, persongroup, and person-supervisor fit. Personnel Psychology, 58, 281-342. doi:10.1111/j.1744-6570.2005.00672.x

Lang, F. R., Lüdtke, O., \& Asendorpf, J. B. (2001). Testgüte und psychometrische Äquivalenz der deutschen Version des Big Five Inventory (BFI) bei jungen, mittelalten und alten Erwachsenen. Diagnostica, 47, 111-21.

Larson, L. M., Rottinghaus, P. J., \& Borgen, F. H. (2002). Meta-analyses of Big Six interests and Big Five personality factors. Journal of Vocational Behavior, 61, 217-239. doi:10.1006/jvbe.2001.1854

Lodi-Smith, J., \& Roberts, B. W. (2007). Social investment and personality: A meta-analysis of the relationship of personality traits to investment in work, family, religion, and volunteerism. Personality and Social Psychology Review, 11, 68-86. doi:10.1177/1088868306294590

McCrae, R. R. (1996). Social consequences of experiential openness. Psychological Bulletin, $120,323-337$.

McCrae, R. R., Costa, P. T., Ostendorf, F., Angleitner, A., Hrebickova, M., Avia, M. D., Sanz, J., et al. (2000). Nature over nurture: Temperament, personality, and life span development. Journal of Personality and Social Psychology, 78, 173-186. doi:10.1037/0022-3514.78.1.173

Meeus, W. (1993). Occupational identity development, school performance, and social support in adolescence: findings of a Dutch study. Adolescence, 28, 809-818. 
Meredith, W. (1993). Measurement invariance, factor analysis and factorial invariance. Psychometrika, 58, 525-543. doi:10.1007/BF02294825

Mortimer, J. T., \& Lorence, J. (1979b). Work experience and occupational value socialization: A longitudinal study. American Journal of Sociology, 84, 1361-1385.

Neyer, F. J., \& Asendorpf, J. B. (2001). Personality-relationship transaction in young adulthood. Journal of Personality and Social Psychology, 81, 1190-1204. doi:10.1037/0022-3514.81.6.1190

Olesen, V. L., \& Whittaker, E. W. (1968). The silent dialogue: a study in the social psychology of professional socialization. San Francisco: Jossey-Bass.

Oleski, D., \& Subich, L. M. (1996). Congruence and career change in employed adults. Journal of Vocational Behavior, 49, 221-229. doi:10.1006/jvbe.1996.0041

Ones, D. S., Dilchert, S., Viswesvaran, C., \& Judge, T. A. (2007). In support of personality assessment in organizational settings. Personnel Psychology, 60, 995-1027. doi: 10.1111/j.1744-6570.2007.00099.x

Ones, D. S., Viswesvaran, C., \& Schmidt, F. L. (1993). Comprehensive meta-analysis of integrity test validities: Findings and implications for personnel selection and theories of job performance. Journal of Applied Psychology, 78, 679-703. doi: 10.1037/00219010.78.4.679

Raudenbush, S. W., \& Bryk, A. S. (2002). Hierarchical linear models: Applications and data analysis methods. SAGE Publications.

Raymark, P. H., Schmit, M. J., \& Guion, R. M. (1997). Identifying potentially useful personality constructs for employee selection. Personnel Psychology, 50(3), 723-736. doi: 10.1111/j.1744-6570.1997.tb00712.x

Roberts, B. W. (2006). Personality development and organizational behavior. Research on Organizational Behavior, 27, 1-40. 
Roberts, B. W., \& Caspi, A. (2003). The cumulative continuity model of personality development: Striking a balance between continuity and. change in personality traits across the life course. In U. M. Staudinger \& U. Lindenberger (Eds.), Understanding human development: Dialogues with lifespan psychology (pp. 183-214). Dordrecht: Kluwer Academic Publishers.

Roberts, B. W., Caspi, A., \& Moffitt, T. E. (2003). Work experiences and personality development in young adulthood. Journal of Personality and Social Psychology, 84, $582-593$.

Roberts, B. W., \& DelVecchio, W. F. (2000). The rank-order consistency of personality traits from childhood to old age: A quantitative review of longitudinal studies. Psychological Bulletin, 126, 3-25. doi:10.1037/0033-2909.126.1.3

Roberts, B. W., Wood, D., \& Caspi, A. (2008). The development of personality traits in adulthood. In O. P. John, R. W. Robins, \& L. A. Pervin (Eds.), Handbook of personality: Theory and research (3rd ed.). (pp. 375-398). New York, NY, US: Guilford Press.

Roberts, B. W., Wood, D., \& Lodi-Smith, J. (2005). Evaluating Five Factor Theory and social investment perspectives on personality trait development. Journal of Research in Personality, 39, 166-184. doi:10.1016/j.jrp.2004.08.002

Rosseel, Y. (2010). lavaan: Latent variable analysis (software). Retrieved from http://lavaan.ugent.be/

Rothstein, M. G., \& Goffin, R. D. (2006). The use of personality measures in personnel selection: What does current research support? Human Resource Management Review, 16, 155-180. doi: 10.1016/j.hrmr.2006.03.004

Scarr, S., \& McCartney, K. (1983). How people make their own environments: A theory of genotype $\rightarrow$ environment effects. Child Development, 54, 424-435. doi: $10.2307 / 1129703$

Schneider, B. (1987). The people make the place. Personnel Psychology, 40, 437-453. doi:10.1111/j.1744-6570.1987.tb00609.x 
Schneider, B., Smith, D. B., Taylor, S., \& Fleenor, J. (1998). Personality and organizations: A test of the homogeneity of personality hypothesis. Journal of Applied Psychology; Journal of Applied Psychology, 83, 462-470. doi:10.1037/00219010.83 .3 .462

Specht, J., Egloff, B., \& Schmukle, S. C. (2011). Stability and change of personality across the life course: The impact of age and major life events on mean-level and rank-order stability of the Big Five. Journal of Personality and Social Psychology, 101, 862-882. doi:10.1037/a0024950

Super, D. E. (1953). A theory of vocational development. American Psychologist, 8, 185-190. doi: $10.1037 / \mathrm{h} 0056046$

Sutin, A. R., \& Costa, P. T. (2010). Reciprocal influences of personality and job characteristics across middle adulthood. Journal of Personality, 78, 257-288. doi:10.1111/j.1467-6494.2009.00615.x

Wille, B., Beyers, W., \& de Fruyt, F. (2012). A transactional approach to person-environment fit: Reciprocal relations between personality development and career role growth across young to middle adulthood. Journal of Vocational Behavior, 81, 307-321. doi:10.1016/j.jvb.2012.06.004

Wagner, G. G., Frick, J. R., and Schupp, J. (2007). The German Socio-Economic Panel Study (SOEP): Scope, Evolution and Enhancements. SOEPpapers on Multidisciplinary Panel Data Research 1, DIW Berlin, The German Socio-Economic Panel (SOEP).

Woods, S. A., Lievens, F., De Fruyt, F., \& Wille, B. (2013). Personality across working life: The longitudinal and reciprocal influences of personality on work. Journal of Organizational Behavior, 34, S7-S25. doi:10.1002/job.1863

Wrosch, C., Scheier, M. F., Miller, G. E., Schulz, R., \& Carver, C. S. (2003). Adaptive selfregulation of unattainable goals: Goal disengagement, goal reengagement, and subjective well-being. Personality and Social Psychology Bulletin, 29, 1494-1508. doi:10.1177/0146167203256921

Wrzesniewski, A. (2001). Crafting a job: Revisioning employees as active crafters of their work. Academy of Management Review, 26, 179-201. 
Tables

Table 1

Means, Standard Deviations, Internal Consistencies, and Stabilities for Big Five Self-Ratings

\begin{tabular}{lcccccccc}
\hline & \multicolumn{2}{c}{2005} & \multicolumn{7}{c}{2009} & & & \\
Personality dimension & $M$ & $S D$ & $\alpha$ & $M$ & $S D$ & $\alpha$ & $r$ \\
\cline { 2 - 8 } & & & & & & & 12 \\
\hline Extraversion & 14.69 & 3.33 & .66 & 14.41 & 3.39 & .67 & .63 \\
Agreeableness & 16.21 & 2.89 & .51 & 15.80 & 2.93 & .52 & .55 \\
Conscientiousness & 18.02 & 2.56 & .60 & 17.76 & 2.60 & .57 & .52 \\
Emotional stability & 12.49 & 3.58 & .61 & 12.86 & 3.57 & .63 & .57 \\
Openness & 13.67 & 3.45 & .60 & 13.29 & 3.49 & .59 & .60 \\
\hline
\end{tabular}


Longitudinal Transactions 37

Table 2

Means, Standard Deviations, Internal Consistencies, and Intercorrelations for the Coding of Personality Role Demand

$\begin{array}{llllllllll}M & S & r_{12} & \boldsymbol{r}_{\boldsymbol{k} t} & 1 & 2 & 3 & 4 & 5\end{array}$

Student ratings

$\begin{array}{llllllllll}\text { 1. Extraversion } & 0.48 & 0.40 & .77 & .57 & .91 & .72 & .05 & .70 & .72\end{array}$

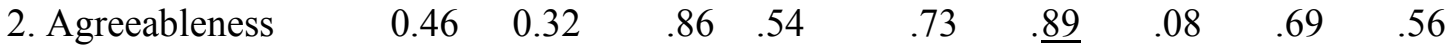

$\begin{array}{llllllllll}\text { 3. Conscientiousness } & 1.14 & 0.32 & .75 & -.06 & .03 & .08 & . \underline{85} & .53 & .16\end{array}$

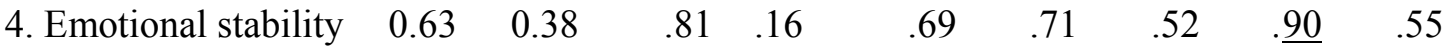

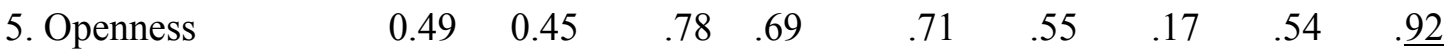

Expert ratings

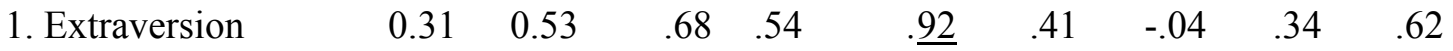

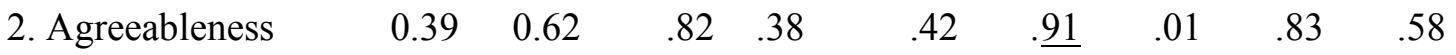

$\begin{array}{llllllllll}\text { 3. Conscientiousness } & 1.39 & 0.51 & .70 & -.14 & -.02 & .04 & .25 & .20 & -.01\end{array}$

$\begin{array}{llllllllll}\text { 4. Emotional stability } & 0.39 & 0.67 & .83 & .03 & .37 & .85 & .21 & . \underline{87} & .45\end{array}$

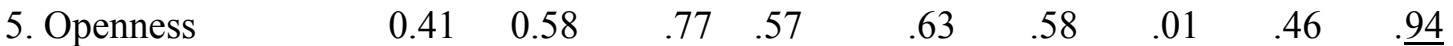

Note. Analyses were based on a pooled sample of job stayer and changer. $N=6991$ for student ratings; $N=6419$ (Wave 1) and 6352 (Wave 2) for expert ratings. $r$ = timely stability (between 2005 and 2009). $r$ = "kernel of truth" correlation between ratings and $k t$

empirical means (aggregated across both waves), which were based on between 109 (expert ratings of frequent Wave 1 professions) and 122 (student ratings of frequent Wave 2 professions) job titles. Within-wave correlations correspond to Wave 1 below the diagonal and Wave 2 above the diagonal. Reliabilities are displayed (underlined) at the diagonal and 
Longitudinal Transactions 38

pertain to the agreement between raters (raters as "items") across 10 students (aggregated importance and typicality ratings) and 4 experts (importance ratings only), respectively. 
Figures

Figure 1

Resulting models for extraversion, agreeableness, emotional stability, and openness to experience

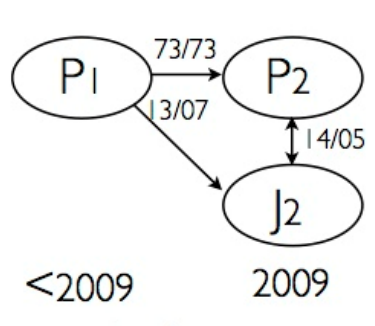

beginners
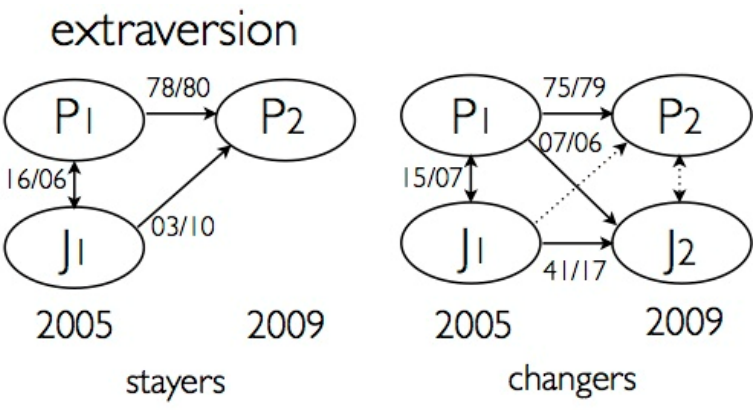

agreeableness
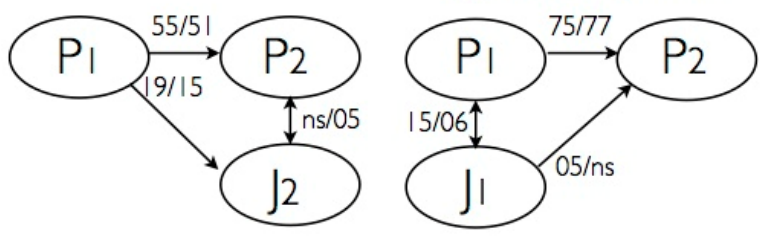

$$
<2009 \quad 2009
$$

beginners

$$
20052009
$$

stayers

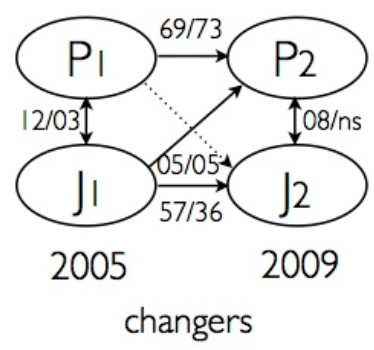

emotional stability
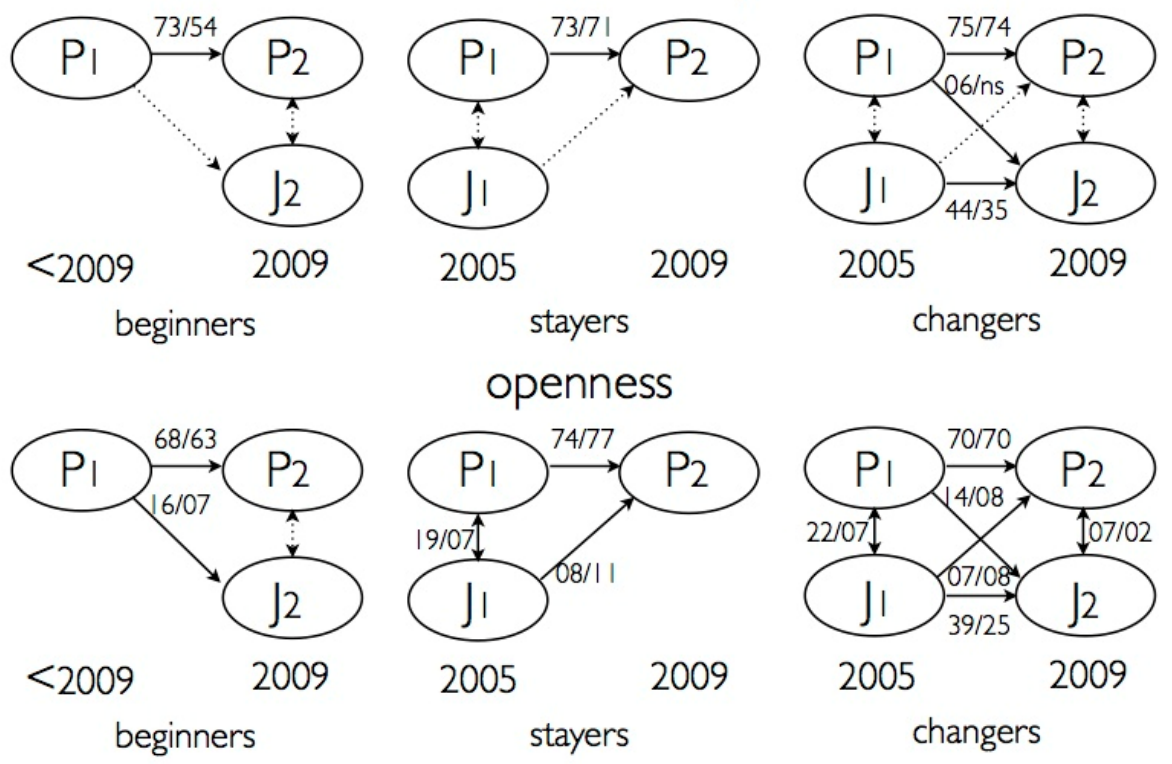

Note. For space reasons, path coefficients are displayed without decimal points. Coefficients on the left side of the slash refer to the student ratings, coefficients on the right to the expert ratings. Paths that were non-significant in both cases are displayed as dotted arrows. 